\title{
Apakah Kepuasan Pelanggan Air Mineral Aqua dipengaruhi oleh Harga dan Kualitas?
}

\author{
Putu Indah Meliyanti ${ }^{* 1}$, Gede Putu Agus Jana Susila² \\ 1,2,Program Studi Manajemen \\ Universitas Pendidikan Ganesha \\ Singaraja, Indonesia
}

\section{e-mail: indahmeliyanti55@gmail.com¹}

Pengutipan: Meliyanti, P.I \& Susila, G. P.A.J. (2021). Pengaruh Harga Dan

Kualitas Produk Terhadap

Kepuasan Pelanggan Air Mineral

Aqua Di Rama Mart. Jurnal Pendidikan Ekonomi Undiksha Vol 13(1), 81-86 http://dx.doi.org/1 0.23887/jipe.v13i $\underline{1.32855}$

\begin{abstract}
Abstrak
Riwayat Artikel Tanggal diajukan: 4 Maret 2021

Tanggal diterima : 17 April 2021

Tanggal dipublikasikan: 25 Juni 2021

Tujuan dari penelitian ini adalah mengamati efek simultan dan parsial dari harga dan kepuasan produk terhadap kepuasan pelanggan. Desain penelitian yang digunakan adalah kausal kuantitatif. Topik penelitian ini adalah klien yang membeli air mineral Aqua di Rama Mart dan item penelitiannya adalah rate, product best, dan kepuasan konsumen. Pendekatan pengambilan sampel yang digunakan berubah menjadi purposive sampling dengan jumlah seratus dua puluh responden. Fakta-fakta dikumpulkan melalui penyebaran kuesioner, kemudian dianalisis dengan alat analisis regresi linier berganda. Hasil penelitian menegaskan bahwa (1) harga dan produk berkualitas tinggi berpengaruh besar dan masif terhadap kepuasan konsumen air mineral aqua di Rama Mart dengan kontribusi $60,5 \%$ berpengaruh, (2) tarif berpengaruh dampak yang luar biasa dan luas terhadap kesenangan pembeli dari pelanggan air mineral aqua di Rama Mart dengan daya 29,5\%, (3) product fine berdampak positif dan luas terhadap kepuasan konsumen air mineral aqua di Rama Mart dengan kontribusi berpengaruh sebesar $23,5 \%$.
\end{abstract}

Kata kunci: harga; kepuasan pelanggan; kualitas produk.

\section{Abstract}

This study goal is to have a look at the impact of rate and product first-rate simultaneously and partially on patron satisfaction. The studies layout used became quantitative causal. The subjects of this studies are customers who buy Aqua mineral water at Rama Mart and the objects of research are charge, product first-rate, and patron pride. The sampling approach used became purposive sampling with a total of a hundred and twenty respondents. information collection changed into achieved by distributing questionnaires, then analyzed via a couple of linear regression evaluation. The results showed that (1) fee and Product high-quality had a tremendous and giant effect on purchaser pride of Aqua mineral water at Rama Mart with a contribution of $60.5 \%$ influence, (2) price had a high-quality and giant impact on Aqua consumer satisfaction. mineral water at Rama Mart. with an influence contribution of 29. five $\%$, (3) Product nice has a high-quality and sizable impact on client delight of Aqua mineral water at Rama Mart with a power contribution of $23.5 \%$.

Keywords : price; customer satisfaction; product quality.

\section{PENDAHULUAN}

Saat ini air minum dalam kemasan (AMDK) merupakan salah satu lembaga yang paling menjanjikan, karena air minum dalam kemasan merupakan produk yang diminati oleh masyarakat, sehingga berkembang pesat di Indonesia. Kebutuhan air mineral dalam kemasan di Indonesia pada 2018 adalah 29 miliar liter dan pada tahun 2019 terjadi peningkatan 
menjadi 30 miliar liter. Jadi semakin tinggi kebutuhan dan permintaan AMDK, menyebabkan semakin tinggi tingkat persaingan diantara produk-produk AMDK. Persaingan yang semakin ketat mengakibatkan konsumen memiliki terdapat banyak pilihan barang dagangan dengan harga yang berbeda-beda dan sangat baik, oleh karena itu menentukan bahwa mereka memiliki harga terbaik di antara beberapa pilihan produk ( $P$ Kotler, 2011). Menyediakan air minum dalam kemasan dengan kualitas terbaik dengan harga yang sesuai tentunya menjadi pilihan masyarakat.

Setiap perusahaan akan berusaha sebaik mungkin untuk memenuhi kebutuhan pelanggannya guna memperoleh kepuasan pelanggan. Yuliarni \& Riyasa (2007) menyatakan bahwa kepuasan klien adalah fungsi dari kinerja berikutnya dan ekspektasi kinerja sebagai perbandingan. Adapun Husein (2003) yang menyatakan kepuasan konsumen adalah penilaian pembelian, kinerja yang dirasakan dari layanan atau produk dari peluang produk yang dipilih memenuhi atau melebihi harapan. Hal ini mengacu pada tingkat pengalaman konsumen setelah membandingkan perasaan atau efeknya dengan harapan Kotler (2011). Kepuasan pelanggan disebabkan oleh kualitas air mineral aqua yang lebih unggul dibandingkan produk lain serta harganya pun menyesuaikan dengan kualitas. Hal ini sesuai dengan Tjiptono (2008:54) produk yang bagus dan harga sangat erat kaitannya dengan kesenangan konsumen, akibatnya pada akhirnya membentuk hubungan yang kuat dengan organisasi. Hubungan ini memungkinkan agensi untuk secara hatihati mengenali ekspektasi klien dan kebutuhan mereka. Sejalan juga dengan penelitian Ofela (2016) yang mendapatkan hasil harga dan kualitas produk yang berdampak besar dan besar pada kepuasan pembeli.

Harga merupakan salah satu variabel yang mempengaruhi kepuasan konsumen. Sejalan dengan Philip Kotler \& Amstrong (2008) harga adalah pendapatan atau nilai yang bersifat pribadi, digunakan, dan atau diperoleh klien dari produk. Assauri (2012:118) harga merupakan beban terhadap suatu produk yang diterima dan digunakan, seperti harga uang yang diterima dari intake, dan biaya sosial non finansial yang meliputi waktu, listrik, psikologi, bahaya, dan atau status sosial. Jika beban harga yang diberikan berkualitas tinggi dan cukup murah, maka akan menjadi panggilan yang bagus untuk konsumen, hobi tambahan dalam produk, dapat menjadi merek dagang kepuasan pelanggan dengan produk tersebut. Jika tarifnya sudah siap sesuai keinginan masyarakat, kepuasan konsumen akan tercipta atas merchandise aqua. Hal ini sesuai dengan teori Lupiyoadi (2014:21) produk bagus yang sama namun dengan biaya yang sangat rendah akan memberikan kepuasan yang lebih tinggi kepada klien.

Selain variabel biaya, kepuasan pelanggan juga merupakan keunggulan produk. Kualitas produk adalah kemampuan suatu produk untuk menjalankan fungsinya yang meliputi daya tahan, efek, akurasi, penghiburan dan keawetan, selain atribut lainnya (Philip Kotler \& Amstrong, 2008:330). Sesuai dengan Oentoro (2010) product fine merupakan komponen terpenting bagi suatu organisasi atau produsen, karena pada kenyataannya product best berkaitan erat dengan kepuasan pelanggan. Jika produk yang memuaskan ideal, itu akan menghasilkan kritik yang sesuai dari pelanggan. Hal ini sesuai dengan konsep Erawan (2004) yang menyatakan bahwa klien dapat merasa puas setelah membeli dan menggunakan merchandise tersebut.

Subjek penelitian ini adalah pelanggan yang membeli air mineral aqua di Rama Mart, karena penjualan air mineral aqua di Rama Mart mengalami peningkatan pada bulan Juli ke Agustus penjualan air mineral aqua mengalami peningkatan sebesar $30,6 \%$ dan pada bulan Agustus ke September kembali mengalami peningkatan sebesar $15,62 \%$. Peningkatan tersebut terjadi karena tingginya kepuasan pelanggan.

Penyebab dari penelitian ini adalah menguji dan menguji hasil dari: (1) kualitas dan harga produk terhadap kepuasan 
pelanggan air mineral aqua di Rama Mart; (2) harga dan kepuasan pelanggan pada aqua mineral water kebanggaan klien di Rama Mart dan; (3) kualitas produk terhadap kepuasan pelanggan aqua mineral water di Rama Mart.

\section{Hubungan Harga dan Kualitas Produk Terhadap Kepuasan Pelanggan}

Konsisten dengan Tjiptono, (2008:54) kualitas produk dan biaya memiliki hubungan yang erat dengan kepuasan pelanggan, untuk alasan ini menjalin hubungan yang kuat dengan perusahaan. Pada akhirnya, hubungan ini memungkinkan perusahaan untuk secara hati-hati memahami ekspektasi klien dan kebutuhan mereka. Zeithaml \& Bitner (2003) berpendapat bahwa kepercayaan adalah melalui kualitas produk dan harga. Mengenai kepuasan konsumen, klien dengan harga atau biaya yang mereka bayarkan untuk produk, serta produk barang yang diandalkan pembeli. Hal ini sejalan dengan penelitian Meisara (2019), pengaruhnya adalah variabel tingkat dan produk luar biasa yang memiliki kualitas tinggi dan berpengaruh besar terhadap kepuasan konsumen.

$\mathrm{H} 1$ : Ada pengaruh tarif dan harga produk terhadap kepuasan konsumen.

\section{Hubungan Harga Terhadap Kepuasan Pelanggan \\ Kepuasan konsumen juga dapat} dilihat berdasarkan harga dimana sebagai alat transaksi agar produk tersebut diperoleh. Apabila harga sesuai dengan persepsi pelanggan maka akan menimbulkan kepuasan dari pelanggan tersebut. Hal ini di dukung teori Alma (2011:169) harga adalah unit ekonomi atau unit ukuran yang berbeda (yang meliputi barang dan persembahan) yang dipertukarkan untuk mengakumulasi kepemilikan atau menggunakan barang dan jasa untuk bertemu dengan klien. Konsekuensi penelitian Rastina, Sudarwanto, \& Wientarsih (2015) menunjukkan bahwa variabel utama yang mempengaruhi kepuasan pembeli adalah variabel tarif.

H2: Terdapat hubungan harga pada tingkat kepuasan pelanggan

\section{Hubungan Kualitas Produk Terhadap Kepuasan Pelanggan}

Produk yang berkualitas merupakan pilihan konsumen atas keunggulan produk. Jika produk berikutnya benarbenar berkualitas dan memenuhi keinginan dan kebutuhan pembeli, itu akan menghasilkan kepuasan konsumen. Philip Kotler \& Armstrong (2008) menyatakan bahwa semakin tinggi tingkat kualitas produk yang memenuhi keinginan pelanggan, semakin baik pula kepuasan pembeli. Hal ini sejalan dengan penelitian Hayati \& Sekartaji (2015) yang menyatakan bahwa produk first-rate memiliki pengaruh yang luar biasa dan krusial terhadap kepuasan pelanggan.

H3: Ada pengaruh kebaikan produk terhadap kepuasan konsumen.

\section{METODE}

Pada penelitian ini peneliti memilih menggunakan desain kausal sebagai metode penelitian agar dapat menguji pengaruh dari masaing -masing variabel. Menurut Sugiyono, (2009) metode ini nantinya akan mengungkapkan hubungan sebab akibat instrumen yang diteliti.

Subjek dalam studi ini yaitu pelanggan yang membeli air mineral aqua di Rama Mart. Objek penelitian ini adalah rate, keunggulan produk dan kepuasan pelanggan. Pengamatan ini menggunakan 120 responden. Pendekatan pengambilan sampel yang digunakan dalam penelitian ini yakni metode purposive sampling dengan kriteria sebagai berikut. (1) Pelanggan yang mengkonsumsi atau membeli air mineral aqua lebih dari tiga kali. (2) Pelanggan yang pernah mengkonsumsi produk sejenis. Bentuk informasi yang digunakan dalam penelitian ini adalah statistik kuantitatif, dan sumber informasi dalam penelitian ini adalah catatan primer dan sekunder.

Teknik statistik yang digunakan dalam penelitian ini adalah pendekatan pencatatan dokumen dan angket. Metode fakta yang digunakan penulis dalam penelitian ini adalah teknik pencatatan dokumen dan angket. Penelitian ini menggunakan lebih dari satu metode evaluasi regresi linier penggunaan paket 
fakta perangkat aplikasi SPSS 20.0 pada windows. Metode yang digunakan untuk menentukan setiap kali biaya variabel independent dan produk berpengaruh besar terhadap variabel kepuasan konsumen yang telah ditetapkan. Sebelum melakukan analisis regresi linier berganda, terlebih dahulu harus memenuhi uji asumsi klasik yang meliputi: (1) uji normalitas, (2) uji heteroskedastisitas, dan (3) uji multikolonieritas.

\section{HASIL DAN PEMBAHASAN}

Hasil

Berdasarkan hasil pengujian SPSS

20.0 pada Windows diperoleh hasil pengujian berupa ringkasan output SPSS seperti nampak pada Tabel 1.

\begin{tabular}{|c|c|c|c|c|c|}
\hline Parameter & Nilai & P-value & $\begin{array}{c}\text { Alpha } \\
(\alpha)\end{array}$ & Keputusan & Simpulan \\
\hline $\operatorname{Ryx}_{1} x_{2}$ & 0,778 & 0,000 & 0,05 & $\begin{array}{c}\text { Menolak } \\
\text { Ho }\end{array}$ & $\begin{array}{l}\text { Ada pengaruh secara simultan } \\
\text { dari harga }\left(\mathrm{X}_{1}\right) \text { dan kualitas } \\
\text { produk }\left(\mathrm{X}_{2}\right) \text { terhadap kepuasan } \\
\text { pelanggan }(\mathrm{Y}) \text {. }\end{array}$ \\
\hline$R^{2} y_{1} x_{2}$ & 0,605 & - & - & - & $\begin{array}{l}\text { Besar sumbangan pengaruh } \\
\text { secara simultan dari harga }\left(\mathrm{X}_{1}\right) \\
\text { dan kualitas produk }\left(\mathrm{X}_{2}\right) \\
\text { terhadap kepuasan pelanggan } \\
\text { (Y). }\end{array}$ \\
\hline$\varepsilon$ & 0,395 & - & - & - & $\begin{array}{l}\text { Besar sumbangan pengaruh } \\
\text { variabel lain terhadap kepuasan } \\
\text { pelanggan }(Y)\end{array}$ \\
\hline $\mathrm{Pyx}_{1}$ & 0,563 & 0,001 & 0,05 & $\begin{array}{c}\text { Menolak } \\
\text { Ho }\end{array}$ & $\begin{array}{l}\text { Ada pengaruh secara parsial } \\
\text { dari harga }\left(\mathrm{X}_{1}\right) \text { terhadap } \\
\text { kepuasan pelangga }(\mathrm{Y}) \text {. }\end{array}$ \\
\hline $\mathrm{P}^{2} \mathrm{yx}_{1}$ & 0,316 & - & - & - & $\begin{array}{l}\text { Menunjukkan besar } \\
\text { sumbangan pengaruh secara } \\
\text { parsial dari harga }\left(\mathrm{X}_{1}\right) \text { terhadap } \\
\text { kepuasan pelanggan }(\mathrm{Y}) \text {. }\end{array}$ \\
\hline $\mathrm{Pyx}_{2}$ & 0,253 & 0,006 & 0,05 & $\begin{array}{c}\text { Menolak } \\
\text { Ho }\end{array}$ & $\begin{array}{l}\text { Ada pengaruh secara parsial } \\
\text { dari kualitas produk }\left(\mathrm{X}_{2}\right) \\
\text { terhadap kepuasan pelanggan } \\
\text { (Y). }\end{array}$ \\
\hline $\mathrm{P}^{2} \mathrm{yx}_{2}$ & 0,064 & - & - & - & $\begin{array}{l}\text { Menunjukkan besar } \\
\text { sumbangan pengaruh secara } \\
\text { parsial dari kualitas produk } \\
\left(\mathrm{X}_{2}\right) \text { terhadap kepuasan } \\
\text { pelanggan }(\mathrm{Y}) \text {. }\end{array}$ \\
\hline
\end{tabular}

kualitas produk terhadap kepuasan pelanggan nampak pada Gambar 1.

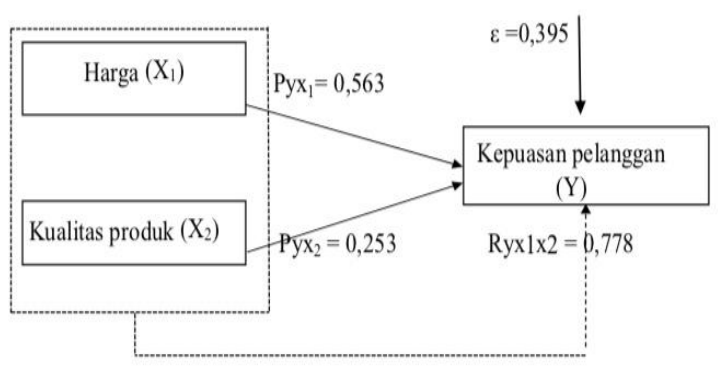

Gambar 1
Struktur Hubungan Pengaruh Harga dan Kualitas Produk Terhadap Kepuasan Pelanggan

Dilihat dari pengaruh uji regresi linier berganda terlihat harga Ryx $1 \times 2=$ 0.778 dengan $p$-value $0,000<\alpha=0,05$, sehingga $\mathrm{HO}$ ditolak, artinya mungkin ada pengaruh dengan harga dan produk berkualitas tinggi pada kepuasan pembeli air mineral aqua di Rama Mart. Kuantitas pengaruh simultan dari biaya dan produk tingkat pertama pada kepuasan pembeli adalah nol. 605 atau $60.5 \%$.

Berdasarkan hasil beberapa penilaian regresi linier menunjukkan biaya Pyx1 $=0,563$ dengan $p$-value nol,036 $<\alpha=$ 0,05 , sehingga $\mathrm{HO}$ ditolak yang artinya ada dampak parsial dari harga kepada kepuasan pelanggan air mineral aqua di Rama Mart. Pentingnya pengaruh biaya terhadap kepuasan klien adalah 0,361 atau $36,1 \%$. Dampak produk terhadap kepuasan pembeli adalah $\mathrm{Pyx} 2=0.253$ dengan $p$-value $0,000<\alpha=0,05$, sehingga $\mathrm{HO}$ ditolak, artinya terdapat pengaruh parsial produk yang besar terhadap kepuasan konsumen aqua mineral air di Rama Mart. Pentingnya pengaruh pengaruh kualitas produk terhadap kepuasan pelanggan adalah 0,064 atau $6,4 \%$.

Berdasarkan konsekuensi dari penilaian regresi linier berganda menjadi menerima biaya yang konsisten ( $\alpha$ ) sebesar 1.845 , biaya koefisien regresi rotasi muatan ( $\beta 1$ ) berubah menjadi nol, dan koefisien regresi produk terbaik ( $\beta 2)$. ) menjadi nol. 254 dan time period blunder $(\varepsilon)$ diubah menjadi 0.395 , sehingga persamaan regresi pada penelitian ini dirumuskan sebagai berikut.

$$
Y=1,845+0,623 X_{1}+0,254 X_{2}+0,395
$$

Penjabaran konsekuensi dari evaluasi regresi linier berganda dalam penelitian ini adalah sebagai berikut. (1) Harga 1,845 mendekati nilai koefisien muatan dan produk terbaik identik dengan 0 , maka kepuasan konsumen 1,845. (2) Harga koefisien harga $(\beta 1)$ sebesar 0,623 berpengaruh efektif terhadap kepuasan pelanggan $(\mathrm{Y})$. Ini berarti bahwa setiap 
satu unit dalam fee (X1), harga kepuasan klien (Y) akan meningkat sebesar 0,623 dengan gagasan bahwa variabel imparsial lainnya adalah regular. (3) Koefisien kenaikan penjualan ( $\beta 2$ ) sebesar 0,254 berpengaruh sangat baik terhadap kepuasan konsumen (Y). Hal ini mengimplikasikan bahwa setiap kenaikan produk kelas satu (X2) adalah satu unit, maka biaya kepuasan pembeli $(\mathrm{Y})$ akan meningkat dengan menggunakan 0,254 dengan asumsi bahwa variabel-variabel tidak berpihak alternatif adalah konstan. (4) error price sebesar 0,395, dengan asumsi selanjutnya untuk rate dan kualitas produk terdapat variabel lain yang mempengaruhi kepuasan klien.

\section{Pembahasan}

Berdasarkan total hasil penelitian yang menunjukkan pengaruh harga dan produk berkualitas tinggi terhadap kepuasan pelanggan air mineral aqua di Rama Mart. Hasil tersebut konsisten dengan Tjiptono (2008:54) kualitas dan harga produk sangat erat kaitannya dengan kepuasan klien dan membentuk interaksi yang kokoh dengan korporasi. Pada akhirnya, interaksi ini memungkinkan perusahaan untuk memahami ekspektasi dan keinginan konsumen. Efek tersebut didukung oleh penelitian yang dilakukan dengan bantuan Meisara (2019) yang menunjukkan bahwa variabel harga dan produk bagus berpengaruh positif dan masif terhadap kepuasan konsumen.

Berdasarkan hasil penelitian secara keseluruhan yang terbukti berpengaruh positif dan biaya yang cukup besar terhadap kepuasan konsumen air mineral Aqua di Rama Mart. Jika tarif sesuai dengan persepsi pelanggan, maka akan menghasilkan kesenangan dari klien. Konsekuensi tersebut sejalan dengan pengumuman Alma (2011:169) bahwa pengeluaran adalah instrumen keuangan atau satuan ukuran lain (yang meliputi barang dan jasa) yang dipertukarkan untuk mengakumulasi kepemilikan atau menggunakan barang dan penawaran untuk bertemu pembeli. Konsekuensi ini didukung oleh penelitian yang dilakukan dengan bantuan Rastina et al. (2015) yang menunjukkan bahwa variabel dominan yang mempengaruhi harga diri klien adalah variabel harga. Berdasarkan studi efek yang telah menunjukkan kualitas tinggi dan pengaruh produk yang sangat besar terhadap kepuasan klien air mineral aqua di Rama Mart. Produk hebat adalah pilihan pelanggan atas kelaziman suatu produk. Jika produk bagus itu ideal dan sesuai dengan keinginan dan kebutuhan klien, maka akan mengarah pada kepuasan konsumen. Philip Kotler \& Amstrong (2008) menunjukkan bahwa semakin tinggi tingkat produk yang luar biasa yang memenuhi kebutuhan konsumen, semakin tinggi kepuasan klien. Hasil tersebut didukung oleh penelitian yang dilakukan dengan bantuan Hayati \& Sekartaji (2015) yang menyatakan bahwa denda produk memiliki pengaruh yang positif dan cukup besar terhadap kepuasan pelanggan.

\section{SIMPULAN DAN SARAN \\ Simpulan}

Berdasarkan total konsekuensi statistik dan hipotesis serta pembahasan yang telah didefinisikan, beberapa simpulan dapat ditarik sebagai berikut. (1) Harga dan produk yang memuaskan berpengaruh besar terhadap kepuasan konsumen air mineral aqua di Rama Mart. (2) Tarif berdampak besar dan besar terhadap kepuasan pembeli air mineral aqua di Rama Mart. (3) Kualitas produk memiliki pengaruh yang berkualitas tinggi dan cukup besar terhadap kepuasan pelanggan air mineral aqua di Rama Mart.

\section{Saran}

Berdasarkan hasil diskusi dan
kesimpulan yang telah dijelaskan sebelumnya, tips selanjutnya dapat dibuat. (1) Bagi peneliti lain, sangat berharap penelitian ini bisa mengembangkan topik penelitian dan memperluas teori variabel yang digunakan dengan menambahkan variabel lain yang mempengaruhi kepuasan konsumen, dan dapat dikembangkan dengan menggunakan teknik analisis data lainnya. Bahan referensi untuk penelitian lebih lanjut dan dapat memperdalam ilmu manajemen. 
(2) Untuk aqua, diharapkan dapat terus memperhatikan harga produk agar tetap terjangkau di masyarakat. Selain itu kualiatas produk juga harus tetap ditingkatkan sehingga dapat mempertahankan kepuasan dari konsumen itu sendiri.

\section{DAFTAR PUSTAKA}

Alma, B. (2011). Manajemen Pemasaran dan Pemasaran. Bandung: Alfabeta.

Assauri, S. (2012). Manajemen Pemasaran. Jakarta: Raja Grafindo Persada.

Erawan, P. (2004). A Synthesis Of A Project For Developing The Management System and School Health Learning Process. Bangkok: Thai Health Promotion Foundation.

Hayati, Y. H., \& Sekartaji, G. (2015). Pengaruh Kualitas Produk Terhadap Kepuasan konsumen Di Restoran Bebek dan Ayam Goreng Pak Ndut Solo. Jurnal IImiah Manajemen Fakultas Ekonomi (JIMFE), 1(1), 4956.

Husein, U. (2003). Metode Riset Prilaku Konsumen Jasa. Jakarta: Ghalia Indonesia.

Kotler, P. (2011). Manajemen Pemasaran, Jilid 1dan 2. Jakarta: PT Indeks Kelompok Gramedia.

Kotler, Philip, \& Amstrong. (2008). DasarDasar Manajemen Pemasaran. Jakarta: PT Indeks.

Kotler, Philip, \& Armstrong, G. (2008). Prinsip-prinsip Pemasaran Jilid 1. Jakarta: Erlangga.

Lupiyoadi, R. (2014). Manajemen Pemasaran Jasa Edisi Ketiga. Jakarta: Salemba Empat.

Meisara, G. V. (2019). Pengaruh Harga Dan Kualitas Produk Terhadap Kepuasan Pelanggan. Jurnail Universitas Utara Malaysia, 7(1), 8595.

Oentoro, D. (2010). Manajemen Pemasaran Modern. Yogyakarta: Laksabang Pressindo.

Ofela, H. (2016). Pengaruh Harga, Kualitas Produk Dan Kualitas Pelayanan Terhadap Kepuasan Pelanggan Konsumen Kebab
Kingabi. Jurnal IImu Riset Manajemen STIESIA, 5(6).

Rastina, Sudarwanto, M., \& Wientarsih, I. (2015). Aktivitas Antibakteri Ekstrak Etanol Daun Kari (Murraya Koenigii) Terhadap Staphylococcus Aureus, Escherichia Coli, Dan Pseudomonas Sp. Jurnal Kedokteran Hewan, 9(2).

Sugiyono. (2009). Metode Penelitian Kualitatif, Kuantitatif, dan R\&D. Bandung: Alfabeta.

Tjiptono, F. (2008). Strategi Pemasaran, Edisi Ke-3. Yogyakarta: Andi offset.

Yuliarni, N., \& Riyasa, P. (2007). Analisis Faktor-faktor Yang Mempengaruhi Kepuasan Pelanggan Terhadap Pelayanan PDAM Kota Denpasar. Bulletin Studi Ekonomi, 12(1).

Zeithaml, V. A., \& Bitner, M. J. (2003). Service Marketing (3rd ed). Tata McGraw Hill, New Delhi. 